\title{
O IMPACTO DO ACORDO DA BASILÉIA SOBRE INSTITUIÇÕES FINANCEIRAS BRASILEIRAS
}

RESUMO

Dentre os problemas que se atribuem à regulamentação bancária, dois se destacam, tanto por sua importância intrínseca como pela freqüência com que são citados: o contingenciamento de crédito decorrente da redução na concessão de empréstimos e financiamentos e o crescimento excessivo da presença de títulos dos governos nos ativos dos bancos. Este estudo se baseou em dados dos cinco maiores bancos de varejo brasileiros e buscou investigar se ocorreram alterações nas estruturas de capitais e de ativos nos últimos anos, devido à regulamentação referente a exigências de capital no contexto do Acordo da Basiléia de 1988. Foram coletados dados dos demonstrativos contábeis dos bancos escolhidos no período de 1990 a 2002, e o estudo se deu pela análise das séries temporais obtidas e pela realização de regressões lineares. Os resultados analisados sugerem novas evidências sobre a influência efetiva das medidas reguladoras sobre as estruturas de capitais e de ativos dos bancos.

\section{Luiz Alberto Bertucci CEPEAD/CAD/UFMG}

\section{Hudson Fernandes Amaral CEPEAD/CAD/UFMG}

\section{Flávio Henrique Ribeiro de Souza}

PUC-Minas e CEPEAD/CAD/UFMG

\begin{abstract}
Among the problems usually attributed to the banking regulation, two are clearly more demanding, because of their intrinsic nature and by the frequency which they are cited: the contingency of credit due to the reduction in the loans and lending volumes, and the excessive growth of government bonds in banks assets composition. The current study is based on data of the five major Brazilian retail banks, and investigates the changes in their assets and capital structures in the last years, due to the regulation of capital requirements in the context of The 1998 Basel Accord. Data from 1990 to 2002 accounting reports have been collected, and the study was build using time series analysis and linear regressions. The results suggest new evidences about the effective influence of regulatory measures on the capital and assets structures of banks.
\end{abstract}

PALAVRAS-CHAVE Regulamentação bancária, acordo da Basiléia, estrutura de capital, títulos públicos, crédito bancário. KEY WORDS Banking regulation, Basel accord, capital structure, public bonds, banking credit. 


\section{INTRODUÇÃo}

A regulação bancária referente a exigências de capital tornou-se, a partir de 1994, com a publicação da norma 2.099/1994 pelo Bacen - Banco Central do Brasil - uma preocupação a mais para os administradores do setor. Além de terem a alavancagem de seus negócios compulsoriamente reduzida por exigências de um capital mínimo para cobrir os riscos de suas operações, tiveram de aperfeiçoar mecanismos de gerenciamento desses riscos e buscar atingir e manter o chamado Índice da Basiléia no patamar mínimo estabelecido pelo agente regulador.

Fixado atualmente em $11 \%$, esse valor mínimo do Índice da Basiléia corresponde à menor razão que deve ser obtida entre um patrimônio exigido e a soma dos ativos ponderados, cada qual por seu fator de risco. Como se trata de uma razão matemática, esse índice pode ser aumentado tanto por incrementos no numerador (patrimônio exigido) como por reduções no denominador (ativos ponderados). Os incrementos no numerador decorrem de operações sofisticadas que diminuam o risco derivado de atividades de balanço e extrabalanço como swaps por exemplo -, da emissão de dívida subordinada ou de aumentos de capital. Já as reduções no numerador podem se dar por diminuição do volume daqueles ativos aos quais se atribui um maior peso na ponderação, pelo aumento do volume daqueles com menor peso ou por ambas as ações conjugadas. Essa substituição de ativos, quando feita de forma a propiciar ao banco o atendimento dos requisitos da resolução sem que tenha de promover aumento de seu capital, é que tem suscitado questionamentos, não só quanto à eficácia das normas reguladoras, mas também quanto a possíveis práticas adotadas pelos gestores dos bancos, tais como a redução no crédito ou a aquisição maciça de títulos do governo.

$\mathrm{O}$ que se buscou investigar com este estudo foram modificações nos ativos que possam ter sido motivadas pela evolução do arcabouço regulador referente às exigências de capital como forma de atingir ou manter o Índice da Basiléia no patamar mínimo estabelecido. A segunda seção deste artigo apresenta as bases teóricas para o estudo. A terceira descreve a metodologia utilizada, e na quarta são apresentados e analisados os resultados obtidos. Finalizando, na quinta seção são apresentadas as conclusões e sugestões para trabalhos futuros.

\section{BASES TEÓRICAS DO ESTUDO}

De acordo com Kashyap, Rajan e Stein (2002), a resposta padrão dos financistas à questão "quais são as características que definem um banco?" é a de que bancos comerciais são instituições engajadas em dois tipos de atividades, uma em cada lado do balanço patrimonial, a saber: captação de depósitos e empréstimos. Para Diamond e Rajan (2001), no lado dos ativos os bancos fazem empréstimos para tomadores em dificuldade e sem liquidez - permitindo desse modo o fluxo de crédito para as empresas - enquanto do lado do passivo eles garantem liquidez conforme ocorra a demanda por parte dos depositantes. Isso envolve uma transformação de ativos, que Diamond e Dybvig (1983) definiram como a capacidade de transformar ativos sem liquidez em demandas de depósitos com necessidade de liquidez imediata.

A existência dos depósitos à vista no passivo faz com que haja a necessidade da manutenção de uma reserva de ativos com liquidez suficiente para o atendimento de demandas aleatórias de saque dos valores depositados. Esses depósitos à vista possuem a vantagem de que por eles não são pagos juros e, assim, seria de se pensar que houvesse interesse de um banco em financiar a maior parte possível de seus ativos com eles. Entretanto, embora não sejam remunerados, os depósitos possuem como desvantagem o fato de que uma fração randômica deles pode ser retirada a qualquer tempo. Conforme Kashyap, Rajan e Stein (2002) e também Flannery (1994), os ativos líquidos que, por causa disso, devem ser mantidos como reserva de liquidez caixa, títulos governamentais, etc. - possuem um peso morto e uma parte dos ganhos é perdida, de forma que o retorno líquido desses ativos é sempre diminuído desse peso, fazendo com que nem sempre o banco mantenha o nível desejado de reserva.

Por outro lado, desde que Miller (1995) mostrou que as proposições de Modigliani e Miller (1958) quanto à irrelevância da estrutura de financiamento se aplicam também aos bancos, inúmeros artigos abordam a aplicabilidade dos modelos teóricos tradicionais às estruturas de capital dessas empresas financeiras, mas as peculiaridades da atividade bancária se fazem sentir de forma importante. Conforme as teorias de agência, firmas alavancadas operam com incentivos de investimento distorcidos, que fazem com que elas abandonem alguns projetos com VPL positivo e adotem outros de VPL negativo. Essas distorções diminuem o valor da firma e os acionistas é que bancam os custos 
dos investimentos inadequados. Entretanto, embora tendo seus incentivos de investimento influenciados pela dívida do mesmo modo que as empresas não-financeiras, os bancos apresentam um elevado grau de alavancagem quando comparados a elas. Isso, evidentemente, os submete a riscos maiores e mais diversificados do que as empresas tradicionais.

Bancos possuem também, como destacado por Flannery (1994), uma peculiar capacidade de se defrontar com oportunidades para realizar a troca de ativos no curso normal de seus negócios e a sucessiva renovação de empréstimos é um veículo para isso. Para Diamond e Dybvig (1983), os ativos dos bancos têm tão pouca liquidez quanto os de outras empresas, mas sua composição pode mudar rapidamente quando comparados aos delas. Essa possibilidade de mudar rapidamente a composição dos ativos cria, por outro lado, segundo Flannery (1994), um risco moral elevado para os bancos.

Lastra (2000) aponta serem três as principais fontes de instabilidade dos bancos: o descasamento da maturidade entre ativos e passivos, a baixa capitalização e a carteira de ativos com riscos. Em particular, a instabilidade gerada pelo descasamento integra as preocupações gerenciais dos administradores bancários e faz com que bancos comerciais sejam especialmente vulneráveis ao que Lastra (2000) e Diamond (1984) denominam de corridas bancárias, devido à relativa falta de liquidez de seus empréstimos, que não podem ser vendidos rapidamente sem deságio, e porque os depósitos são direitos não-contingentes, ou seja, podem ser sacados por pedido e a qualquer momento. Dessa forma, com a consagração pelos países do sistema de reserva fracionado, a qualquer instante um banco pode tornar-se incapaz de cumprir com todas as suas obrigações se tiver que convertê-las de imediato em dinheiro.

Na verdade, são todas essas peculiaridades dos bancos quanto à liquidez, solvência e riscos, além das externalidades negativas que podem produzir na economia, que geram a necessidade da regulamentação bancária, que, por sua vez, influencia as ações dos administradores.

No Brasil, a primeira norma reguladora que seguiu o Acordo da Basiléia de 1988 foi editada em 1994 e a ela se seguiram inúmeras outras. Em seu formato atual, as exigências de capital podem ser traduzidas na fórmula:

$$
\mathrm{PLE}=\mathrm{F} \cdot \mathrm{APR}+\mathrm{F}^{\prime} \cdot \sum \mathrm{RCD}_{\mathrm{i}}+\mathrm{F}^{\prime} \cdot \mathrm{Max}\left\{\left(\sum \mathrm{APRCi}-\mathrm{K} \cdot \mathrm{PR}\right) ; 0\right\}+\sum \mathrm{EC}_{\mathrm{i}}
$$

em que:

PLE = patrimônio líquido exigido;

$F$ = fator aplicável ao APR, equivalente a 0,11 ;

$A P R=$ ativo ponderado pelo risco;

$F^{\prime}$ = fator aplicável ao risco de crédito das operações de swap, igual a 0,20 ;

$R C D_{i}=$ risco de crédito da i-ésima operação de swap inscrita na conta contábil apropriada, consistente na ponderação do valor de referência da operação no momento da respectiva contratação $\left(V N_{i}\right)$ pelo fator de risco potencial correspondente, considerado seu prazo a decorrer, dado pela fórmula:

$$
\mathrm{RCD}_{\mathrm{i}}=\mathrm{VN}_{\mathrm{i}} \sqrt{\mathrm{Ra}_{\mathrm{i}}^{2}+\mathrm{Rp}_{\mathrm{i}}^{2}+2 \rho_{\text {rai, } \mathrm{i}} \cdot \mathrm{Ra}_{\mathrm{i}} \cdot \mathrm{Rp}_{\mathrm{i}}}
$$

em que:

$V N_{i}=$ valor de referência da operação no momento da contratação;

$r_{\text {rai, pi }}=$ correlação entre os referenciais ativo e passivo da i-ésima operação;

$R a_{i}=$ risco do ativo referencial da i-ésima operação (desvio padrão);

$R_{p i}=$ risco do passivo referencial da i-ésima operação (desvio padrão);

Obs: o somatório de $R C D_{i}$ varia de 1 até o número de operações de swap inscritas na conta contábil correspondente;

F" = fator aplicável às operações com ouro e com ativos e passivos referenciados em variação cambial, incluídas aquelas realizadas nos mercados de derivativos, igual a 0,50 (cinqüenta centésimos);

$A P R C_{i}=$ valor das posições líquidas das operações com ouro e com ativos e passivos referenciados em variação cambial, incluídas aquelas realizadas nos mercados de derivativos;

Obs : O somatório de $A P R C_{i}$ varia de 1 até o número de operações em cada moeda e ouro;

$K=0,05$ se o (somatório de $A P R C / P R$ ) for menor ou igual a 0,05 e zero se for maior;

$P R=$ Patrimônio de Referência, apurado nos termos da resolução 2.837/2001;

$E c i=$ parcela representativa do valor de PLE para cobertura do risco de mercado de taxa de juro em determinada moeda/base de remuneração.

Obs: O somatório varia de 1 até o número de parcelas representativas do valor de PLE para cobertura do risco de mercado de taxa de juros em determinada moeda/base de remuneração. 
O primeiro termo da equação é o termo da formulação original do acordo da Basiléia, sendo que o coeficiente $F$, que originalmente valia $0,08(8 \%)$ e, no Brasil, foi alterado para 0,11 (11\%), é o que ficou conhecido com Índice da Basiléia.

De uma forma mais genérica, podemos reescrever (1) como:

$$
\text { F.APR }=P L E-R_{1}-R_{2}-R_{3}
$$

$\mathrm{ou}$

$$
\mathrm{F}=\frac{\left(\mathrm{PLE}-\mathrm{R}_{1}-\mathrm{R}_{2}-\mathrm{R}_{3}\right)}{\mathrm{APR}}
$$

Com $F$ (atualmente, no Brasil) valendo 0,11 e onde: $R_{1}$ - Risco derivado das operações com swaps.

$R_{2}$ - Risco derivado da exposição a operações com ouro e moeda estrangeira, $e$

$R_{3}$ - Risco de Mercado para taxas de juros.

Além dos impactos dessa formulação sobre a alavancagem dos bancos, a questão que interessa aqui, um dos pontos cruciais das exigências, diz respeito aos ativos ponderados. Em primeiro lugar, é importante observar que foram estabelecidos quatro níveis de risco (fatores de ponderação $0 \%, 20 \%, 50 \%$ e $100 \%$ ) como ponderadores da média dos ativos. Assim, títulos governamentais, por exemplo, foram considerados de risco zero, enquanto créditos interbancários receberam o peso de $20 \%$. No outro extremo, os créditos ao setor privado não-bancário tornaram-se computáveis em $100 \%$ de seu valor. Essa ponderação dos ativos relaciona-se, naturalmente, com a capacidade, citada por Flannery (1994), que os bancos possuem de promover a troca de ativos no curso de seus negócios.

Se considerarmos as dificuldades de se aumentar capital, apontadas pelos financistas, a troca de ativos pode se apresentar como uma solução atraente para a manutenção do índice acima do patamar mínimo requerido. Entretanto, muitas são as críticas a esse tipo de operação. Para Canuto (2001a), o objetivo de aproximar a regulação dos bancos à complexidade de suas operações, com a introdução da consideração sobre a heterogeneidade dos ativos, não só não foi atingido como a velocidade das transformações financeiras fez aumentar ainda mais o descompasso entre essa complexidade e a diferenciação de riscos reconhecida no acordo. Mais ainda, para esse autor, a diferenciação de ativos contida nas regras do acordo pode promover incentivos a práticas bancárias cujo resultado é diminuir a qualidade média dos créditos nas carteiras.

Um outro tipo de questionamento importante surge da potencial restrição ao crédito que existe na ponderação dos ativos. A dúvida é se o dilema entre uma maior estabilidade bancária versus o cumprimento da função de suporte econômico dos bancos pode ser tratada da mesma forma em países desenvolvidos e em países emergentes. Canuto (2001b) pontua que o exame de um número amplo de economias emergentes que adotaram e endureceram a regulação de capital bancário doméstico nos anos 90 mostra que os requisitos mais elevados de capital mínimo têm consequêencias ainda mais duras sobre os empréstimos bancários e os gastos privados nas economias emergentes. Ressalta ainda que os efeitos restritivos ao crédito não se apresentam apenas nos momentos iniciais da implantação da regulação, surgindo impactos decorrentes dos novos padrões de adequação de capital que independem dos ciclos econômicos.

Em pesquisa do IPEA - Instituto de Pesquisa Econômica Aplicada - Soares (2001) sugere um papel relevante da norma prudencial brasileira (Res. 2.099/ 1994) na conformação dos níveis e da composição do crédito bancário, entre títulos públicos e o crédito ao setor privado. Segundo essa pesquisa, a adesão brasileira ao acordo da Basiléia, concretizada na resolução, intensificou a atratividade relativa da aplicação bancária em títulos públicos federais. Essa observação ratifica as críticas ao fato de que esse e outros aspectos distorcem a aplicação do acordo da Basiléia em países emergentes, fazendo até com que, eventualmente, os bancos sejam enfraquecidos, e não fortalecidos.

\section{METODOLOGIA}

Para a realização do estudo, foram utilizadas duas técnicas amplamente descritas nos manuais de estatística e econometria: a análise de séries temporais e a regressão linear simples. Mais especificamente, utilizaram-se regressões de séries temporais umas nas outras, como forma de verificar o tipo e a intensidade da interação existente entre a evolução temporal dessas séries. Foram tomados os devidos cuidados no sentido de evitar as chamadas regressões espúrias, nas quais, se as séries regredidas mantêm ambas uma forte ten- 
dência sustentada, a coincidência nessas tendências pode gerar uma pseudoforte influência de uma variável sobre a outra, tornando não-confiáveis as estatísticas $\mathrm{t}$ e $\mathrm{F}$.

A verificação de estacionariedade das séries seguiu as recomendações habituais dos manuais; e utilizouse aqui o teste ADF - Augmented Dickey-Fuller -, no qual uma estatística $\tau$ corresponde à distribuição $\mathrm{t}$ de Student e é confrontada com valores críticos préestabelecidos para efeitos de rejeição de uma hipótese nula em que $\rho=1$, ou seja tem-se uma série nãoestacionária.

São as séries não-estacionárias as que podem gerar as chamadas regressões espúrias, em que as estatísticas t e F se tornam não-confiáveis. Nesse sentido, os testes de cointegração são uma forma de se prevenir dessa ocorrência. A existência de cointegração sinaliza um equilíbrio que irá provavelmente se estabelecer, sugerindo existir uma relação de longo prazo que retorna a confiabilidade às estatísticas t e $\mathrm{F}$. A idéia de cointegração se relaciona com a idéia de sincronicidade dos movimentos oscilatórios das tendências. É como se, no dizer de Gujarati (1988), séries cointegradas apresentassem movimentos oscilatórios com o mesmo comprimento de onda, quer dizer, com tendências que interagem, como na interferência construtiva entre ondas.

Aqui utilizou-se o teste de Johansen, que aponta diretamente, a um determinado nível de significância, a probabilidade de rejeição das hipóteses nulas de nãoexistência de cointegrações, da existência de no máximo uma, no máximo duas cointegrações, e assim por diante, até um limite em que não seja mais possível examinar.

Finalmente, conforme Gujarati (1988), como estabelecido por Granger, a própria relação entre o coeficiente $R^{2}$ e o coeficiente d de Dubin-Watson já é um indicativo importante, sendo que a ocorrência $R^{2}>d$ já constitui, por si só, uma boa regra prática para suspeitar de que a regressão estimada sofre de regressão espúria.

Para a realização do estudo foram definidas as seguintes variáveis:

$$
\begin{aligned}
& \text { PLCAP }=\frac{\text { Patrimônio Líquido }}{\text { Ativos }} \\
& \text { TVMRAT }=\frac{\text { Títulos }+ \text { Valores Mobiliários }}{\text { Ativos }}
\end{aligned}
$$

e

$$
\text { CRERAT }=\frac{\text { Crédito }}{\text { Ativos }}
$$

em que:

patrimônio líquido, ativos, títulos e valores mobiliários e crédito correspondem a contas contábeis do plano de contas das instituições bancárias (Cosifs). Como o Banco Central não exige (ou não divulga) a composição exata da carteira de títulos dos bancos, a conta correspondente a títulos e valores mobiliários foi utilizada como proxy para títulos sem risco, na suposição de que, por suas características, os bancos pesquisados operam predominantemente com títulos federais (risco zero).

Foram montadas e analisadas as séries temporais das variáveis em estudo, sendo que tanto numerador como denominador correspondem às somas dos numeradores e denominadores individuais dos bancos componentes da amostra. Em seguida, foram rodadas as regressões simples entre PLCAP relativamente a TVMRAT e CRERAT.

Foram considerados os dados dos balanços trimestrais de março de 1990 a setembro de 2002, disponíveis no site do Bacen, dos seguintes bancos: Bradesco, Itaú, Unibanco, ABN AMRO e Safra. Por qualquer critério que se queira adotar (ativos, depósitos, agências, etc.), esses bancos representam uma amostra significativamente representativa da população de bancos de varejo brasileiros.

\section{APRESENTAÇÃO E ANÁLISE DOS RESULTADOS}

A Tabela 1 mostra o teste ADF para verificação da estacionariedade das séries. Os valores críticos correspondem, de cima para baixo, a níveis de significância de $1 \%, 5 \%$ e $10 \%$. O Gráficol mostra a evolução temporal de PLCAP, TVMRAT e CRERAT. No eixo $\mathrm{x}$ do gráfico, a escala vai de 1 a 51, correspondendo aos respectivos trimestres, ou seja, 1 corresponde a março de 1990, 5 corresponde a março de 1991, e assim por diante. A Tabela 2 mostra as correlações entre PLCAP, TVMRAT e CRERAT e, finalmente, a Tabela 3 mostra o resultado das regressões.

Conforme demonstrado na Tabela 1 , a variável PLCAP, que mede a razão entre o patrimônio líquido e os ativos, é não-estacionária somente para níveis de 
significância de 5\% e 10\%, enquanto TVMRAT, que mede a razão entre títulos e valores mobiliários e os ativos é uma random walk do tipo I, ou seja, não-estacionária, tendo sua série das primeiras diferenças estacionária, para qualquer nível de significância. Já a variável CRERAT, mensuradora da razão entre crédito e ativos, representa uma série estacionária.

Essas condições de estacionariedade descartam problemas com CRERAT, mas sugerem a possibilidade de regressões espúrias envolvendo PLCAP e TVMRAT, pelo que foram feitos os testes de Johansen e encontrada pelo menos uma cointegração entre essas variáveis.

A evolução da variável PLCAP, que pode ser visualizada no Gráficol, mostra que em 1990, iniciase uma tendência crescente na capitalização dos bancos estudados, que se inverte no final de 1991, mantendo-se em média decrescente até próximo da edição das primeiras normas sobre adequação de capital. De fato, no final de 1993/início de 1994 os bancos encontravam-se com níveis baixos de capitalização se comparados com os do resto do período analisado, e superiores somente ao início de 1990.

Ainda no Gráfico 1, é possível verificar que de 1994 a 1995, a capitalização aumenta, atingindo um pico, próximo ao início de 1995, sem retomar, entretanto, os níveis mais altos de capitalização atingidos no pe- ríodo. A partir daí, a influência estocástica das tendências da variável se faz sentir fortemente, gerando grandes oscilações, tendo ela, contudo, apresentado uma tendência em média decrescente, terminando o período analisado indicando níveis de capitalização superiores em relação a 1990, mas inferiores se comparados com 1995 ou com 1991 - anos em que apresentaram seus níveis mais elevados.

Se observarmos a fórmula de PLCAP - razão entre patrimônio líquido e ativos - e considerarmos que todo o período posterior a 1994 representa um período de expansão de ativos, conforme consta nos boletins do próprio Bacen, concluímos a inexistência de uma influência forte e permanente decorrente das medidas reguladoras sobre o nível de capitalização dos bancos, medido por PLCAP. Ocorre uma elevação da capitalização (redução da alavancagem) logo após a resolução inicial do Bacen, mas ela não se mantém, ocorrendo, em seguida, uma queda na proporção PL/Ativos.

Considerando-se que já ao final de 2000, quando a divulgação dos índices da Basiléia para os bancos passa a ser obrigatória e possivelmente até mesmo antes, todos os bancos da amostra - e quase todos os privados, em geral - apresentavam índices satisfatórios, acima dos $11 \%$ mínimos. Os resultados sugerem que aumentos na capitalização não foram o único e nem

Tabela 1 - Teste ADF para as variáveis em estudo.

\begin{tabular}{|c|c|c|c|c|}
\hline $\begin{array}{ll}\text { VARIÁVEIS } & \text { TESTE } \\
\end{array}$ & $\begin{array}{c}\text { ESTATÍSTICA } \tau \text { PARA } \\
\text { A SÉRIE }\end{array}$ & $\begin{array}{l}\text { VALORES } \\
\text { CRÍTICOS }\end{array}$ & $\begin{array}{c}\text { ESTATÍSTICA } \tau \text { PARA } \\
\text { DIFERENÇAS PRIMEIRA ORDEM }\end{array}$ & $\begin{array}{l}\text { VALORES } \\
\text { CRÍTICOS }\end{array}$ \\
\hline \multirow{3}{*}{ PLCAP } & \multirow{3}{*}{$-2,6699$} & $-3,5682$ & \multirow{3}{*}{$-5,4000$} & $-3,5713$ \\
\hline & & $-2,9215$ & & $-2,9228$ \\
\hline & & $-2,5983$ & & $-2,5990$ \\
\hline \multirow{3}{*}{ TVMRAT } & \multirow{3}{*}{$-1,7304$} & $-3,5682$ & \multirow{3}{*}{$-4,8236$} & $-3,5713$ \\
\hline & & $-2,9215$ & & $-2,9228$ \\
\hline & & $-2,5983$ & & $-2,5990$ \\
\hline \multirow{3}{*}{ CRERAT } & \multirow{3}{*}{$-3,5780$} & $-3,5682$ & \multirow{3}{*}{$-6,2548$} & $-3,5713$ \\
\hline & & $-2,9215$ & & $-2,9228$ \\
\hline & & $-2,5983$ & & $-2,5990$ \\
\hline
\end{tabular}

Tabela 2 - Matriz de correlação entre as variáveis em estudo.

\begin{tabular}{|l|l|l|l|}
\hline VARIÁVEIS & PLCAP & TVMRAT & CRERAT \\
\hline PLCAP & 1,0000 & & \\
\hline TVMRAT & $-0,2011$ & 1,0000 & 1,0000 \\
\hline CRERAT & 0,1508 & $-0,1765$ & \\
\hline
\end{tabular}


sequer o principal arranjo para o atingimento ou para a manutenção desses índices satisfatórios da Basiléia por parte dos bancos privados brasileiros; ainda mais, tais resultados apontam para uma provável utilização de mecanismos alternativos, sendo que aqui interessa a análise daqueles eventualmente sugeridos pelas modificações nas variáveis mensuradoras dos ativos em estudo.

O fato de CRERAT - razão entre crédito e ativos ser estacionária sugere a estagnação da oferta de crédito, e podemos visualizar no Gráfico 1 a estabilização dessa variável logo após um declínio no final de 1994 que interrompe um crescimento iniciado em 1992. Por outro lado, a verificação na Tabela 3 do p-value associado ao coeficiente angular obtido na regressão de PLCAP em CRERAT sugere a ausência de relacionamentos entre as duas variáveis. Também na
Tabela 3 é possível constatar a existência de um relacionamento inverso entre CRERAT e TVMRAT e isso pode significar o crescimento dos títulos em carteira, medidos por TVMRAT, em conseqüência da diminuição do crédito, medido por CRERAT, num processo de migração de ativos.

Ainda com relação a TVMRAT, que mede a razão entre títulos e valores mobiliários e ativos, a análise do $p$-value da regressão com PLCAP, também apresentado na Tabela 3, sugere cautela no que diz respeito ao relacionamento inverso entre elas, apontado pelo sinal do coeficiente angular. Contudo, o p-value observado cai para 0,0045 quando a regressão é feita considerando-se somente o período posterior a 1994, o que, aí sim, sugere, de forma bastante forte, a utilização da carteira de títulos como mecanismo alternativo aos aumentos de capital. A análise da evolução temporal

Tabela 3 - Regressões simples entre as variáveis em estudo - dependente ou explicada.

\begin{tabular}{|l|c|c|c|c|c|c|}
\hline \multirow{2}{*}{ TESTE } & $\begin{array}{c}\text { VARIÁVEL } \\
\text { EXPLICATIVA }\end{array}$ & \multicolumn{1}{|c|}{$\mathrm{R}^{2}$} & $\begin{array}{c}\text { DURBIN- } \\
\text { WATSON }\end{array}$ & $\begin{array}{c}\text { COEFICIENTE } \\
\text { ANGULAR }\end{array}$ & DESVIO PADRÃO & P-VALUE \\
\hline \multirow{2}{*}{ VARIÁVEL } & TVMRAT & 0,0404 & 0,5117 & $-0,0742$ & 0,0517 & 0,1571 \\
\hline \multirow{2}{*}{ PLCAP } & CRERAT & 0,0227 & 0,4849 & 0,0916 & 0,0858 & 0,2908 \\
\hline CRERAT & TVMRAT & 0,1855 & - & $-0,2939$ & 0,1073 & 0,0090 \\
\hline
\end{tabular}

Gráfico 1 - Evolução temporal das variáveis estudadas.

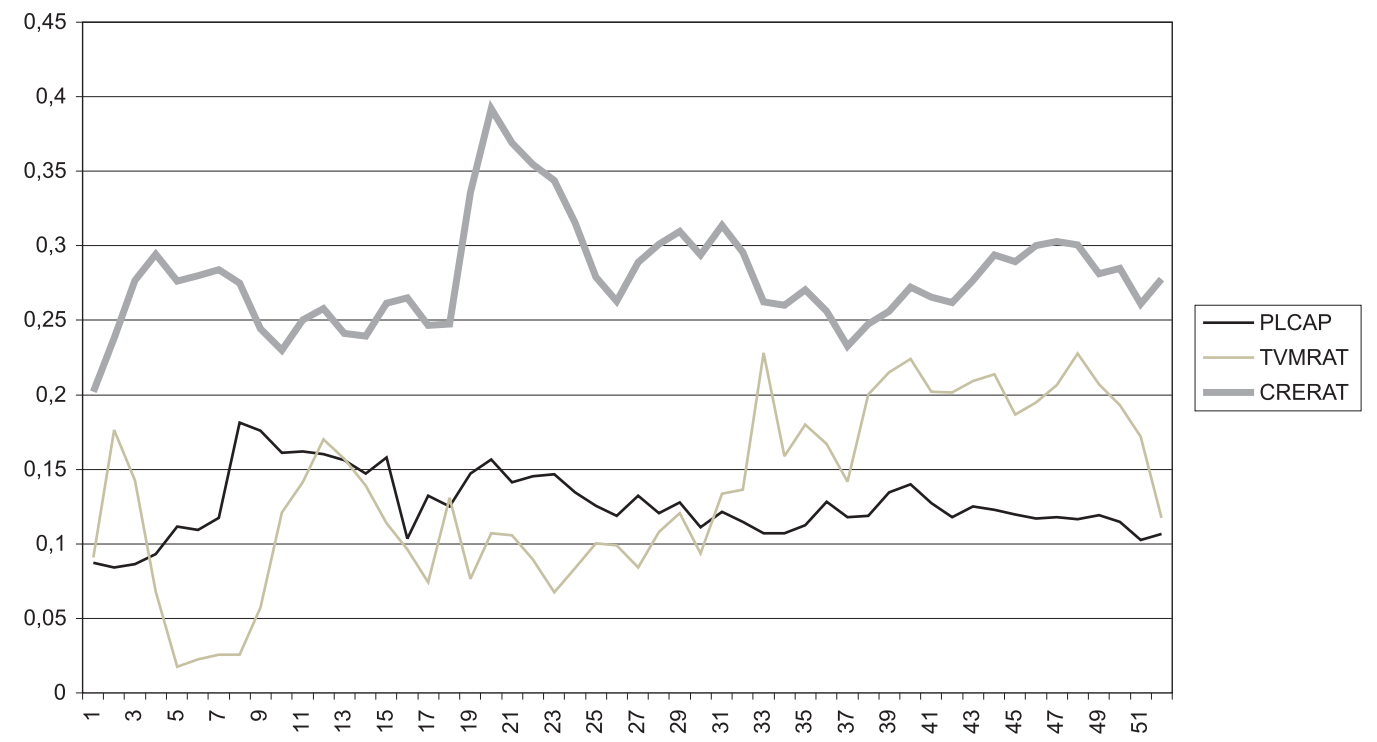


de TVMRAT, que pode ser visualizada no Gráficol, mostra que, de fato, ocorreu um aumento da participação dos títulos e valores mobiliários nos ativos dos bancos. Embora apresente ao final do período analisado uma tendência decrescente, a variável vem de um pico em 2001 e apresentou uma tendência em média crescente entre 1994 e 2001. Além disso, o estudo sugere uma correlação desse crescimento com fases de redução no capital relativo medido por PLCAP.

\section{CONCLUSÕES E SUGESTÕES}

Em primeiro lugar, é importante destacar a heterogeneidade das características e do comportamento dos bancos brasileiros, bem como das respostas gerenciais que são dadas aos problemas que a eles se apresentam. Observou-se isso no estudo e, assim sendo, tanto as séries como os resultados obtidos representam uma tendência média que não coincide, necessariamente, com o comportamento individual dos bancos. Por isso, a primeira leviandade que se comete ao fazer colocações do tipo "a regulação gerou um contingenciamento de crédito" é generalizar um comportamento que ignora essa diversidade dos bancos brasileiros, amplamente confirmada nesse estudo.

Assim, não parece ser possível afirmar, por exemplo, que, de um modo geral, os bancos responderam às exigências de adequação de capital com o aumento dos títulos federais em suas carteiras em detrimento do crédito. A análise do Banco Itaú, por exemplo, se conduzida individualmente, aponta uma correlação importante entre suas posições em títulos e valores mobiliários em face da estrutura de financiamento, o que não ocorre com Bradesco e Safra, resultando na inexistência da correlação para o grupo.

As diferenças são notáveis e se revelaram por todo o estudo, questionando qualquer critério de senso comum (tamanho, ativos, capitalização atual) que se buscasse para tentar agrupar bancos com respostas homogêneas ao problema em estudo. Dessa forma, restou falar em resultados indicativos da tendência média do grupo, e restou também a conclusão sobre esse caráter heterogêneo das respostas gerenciais a um mesmo problema, surgido em um mesmo ambiente. Quiçá, a flexibilidade adquirida com os sucessivos períodos de intempéries econômicas tenha levado os bancos ao paroxismo de uma criatividade gerencial que praticamente personaliza as respostas às necessidades oriundas do ambiente.
Com relação às questões específicas do estudo, todos os bancos estudados responderam com uma elevação inicial de seus níveis de capital, logo após a edição das primeiras medidas contendo requerimentos adicionais de capital. Depois dessa elevação inicial, todos os bancos apresentaram também declínios nas proporções de patrimônio líquido em relação aos ativos. Por outro lado, esse declínio parece acompanhado de movimentos nos ativos que sinalizam restrições ao crédito e crescimento de títulos em carteira dele decorrentes.

Um estudo mais amplo da evolução das normas reguladoras mostra que, se por um lado, com o passar do tempo, foram aumentando os requerimentos de capital, por outro se atenuou a restrição inicial à alavancagem, com a inclusão no patrimônio de referência de elementos como a dívida subordinada, além de outras modificações que restauraram, de certa forma, boa parte da liberdade de ação dos bancos com relação ao endividamento.

O fato de que todos os bancos estudados - o que se depreende das notas de balanço - passaram a utilizar dívida subordinada com mais frequência, o cuidado gerencial que demonstram na gestão do risco decorrente da exposição cambial e do uso de derivativos e swaps - que também se evidencia nas notas -, combinado com as tendências encontradas nesse estudo, sugere que diversos mecanismos combinados possam estar sendo utilizados como alternativa aos movimentos de capital, conferindo aos bancos uma maior liberdade no que se refere à determinação de suas estruturas de capital.

Desse modo, o que esses movimentos parecem sinalizar é a preservação, apesar do arcabouço regulador, do poder estratégico dos bancos de manusear suas estruturas de capital e de ativos. Num processo que é bastante dinâmico, tanto os agentes reguladores parecem haver considerado a necessidade de não restringir demais os bancos, como eles se valeram das "brechas" criadas para liberar suas decisões sobre ativos e passivos de mais esse fator influente.

Finalmente, se a finalidade principal das medidas reguladoras, implementadas no Brasil pelo Bacen com o objetivo explícito de diminuir riscos, foi aumentar o capital protetor dos bancos aos diversos riscos decorrentes da atividade bancária, esse aumento não se traduziu na necessidade efetiva de aumento da relação capital/ativos, e mecanismos outros que não o aumento efetivo de capital parecem estar sendo utilizados. Isso coloca questões importantes como: "será que o 
aumento dos títulos governamentais no portfólio de ativos melhora de fato sua qualidade?", "os demais componentes do capital protetor que não o capital propriamente dito - como a dívida subordinada por exemplo - representam, de fato, um fator de proteção?", "Restrições ao crédito advindas da migração de ativos não seriam prejudiciais a economias emergentes como a brasileira?"

Essas questões se juntam a outras e sugerem uma ampla gama de possibilidades de estudos futuros, notadamente os que criem modelos teóricos ou empíricos que permitam a inclusão de um número crescente de variáveis, uma vez que a quantidade de informações aumenta dia a dia, na análise do problema das estruturas de capital e de ativos dos bancos sob a influência de um ambiente complexo e volátil, integrado, dentre outras coisas, pela ação dos agentes reguladores.

Artigo recebido em 26.09.2003. Aprovado em 09.01.2004.

\section{Referências bibliográficas}

CANUTO, O. O evolucionismo do novo acordo da Basiléia. 2001a. Disponível em http://www.eco.unicamp.br/artigos/artigol62.htm. Acesso em: 04 jul. 2002
CANUTO, O. Requisitos draconianos de capital bancário. 2001b. Disponível em http://www.eco.unicamp.br/artigos/artigo201.htm. Acesso em: 13 ago. 2002

DIAMOND, D. W. Financial intermediaries and delegated monitoring. Review of Economic Studies, v. 51, n. 3, p.393-414, 1984.

DIAMOND, D. W.; DYBVIG, P. Bank runs, deposit insurance and liquidity. Journal of Political Economy, v. 91, n. 3, p. 393-414, 1983.

DIAMOND, D. W.; RAJAN, R. G. Liquidity risk, liquidity creation, and financial fragility: a theory of banking. Journal of Political Economy, v. 109, n. 2 , p. $287-326,2001$.

FLANNERY, M. J. Debt maturity and the deadweight cost of leverage: optimally financing banking firms. The American Economic Review, v. 84, n. 1, p. 320-331, 1994

GUJARATI, D. N. Basic econometrics. 2ª ed. New York: Mc Graw Hill, 1988.

KASHYAP, A. K.; RAJAN, R.; STEIN, J. C. Banks as liquidity providers: an explanation for the coexistence of lending and deposit-taking. The Journal of Finance, v. LVII, n. 1, p. 33-73, 2002.

LASTRA, R. M. Banco central e regulamentação bancária. Belo Horizonte: Del Rey, 2000.

MILLER, M. H. Do the M\&M propositions apply to banks? Journal of Banking and Finance, v. 19, n. 6, p. 439-489, 1995.

MODIGLIANI, F; MILLER, M. H. The cost of capital, corporation finance, and the theory of investment. American Economic Review, v. 48, n. 3, p. 261-97, 1958.

SOARES, R. P. Evolução do crédito de 1994 a 1998: uma explicação. Brasília, DF: IPEA, 2001. p. 1-48 (Texto para Discussão, n. 808).

\section{Luiz Alberto Bertucci}

Professor Adjunto do CEPEAD/CAD/UFMG. Doutor em Finanças pela FGV-EAESP. Interesses de pesquisa em finanças corporativas, gerenciamento de riscos, instituições financeiras.

E-mail: bertucci@face.ufmg.br

Endereço: Rua Curitiba, 832, Centro, Belo Horizonte - MG, 30170-120.

\section{Hudson Fernandes Amaral}

Professor Adjunto do CEPEAD/CAD/UFMG. Doutor em Finanças pela Université Pierre Mendès France - Grenoble II, França. Interesses de pesquisa em finanças corporativas, fundos de investimentos, finanças públicas, mercado de capitais e derivativos.

E-mail: hfamaral@face.ufmg.br

Endereço: Rua Curitiba, 832, Centro, Belo Horizonte - MG, 30170-120.

Flávio Henrique Ribeiro de Souza

Professor Assistente da PUC-Minas e Colaborador no NUFI (Núcleo de Finanças do CEPEAD/CAD/UFMG). Mestre em Administração pela PUC-Minas. Interesses de pesquisa em bancos, gerenciamento de riscos, fundos de investimentos. E-mail: flavihenrique@uol.com.br Endereço: Rua Curitiba, 832, Centro, Belo Horizonte - MG, 30170-120. 